\title{
Analysis of load-slip characteristics of nailed wood joints: application of a two-dimensional geometric nonlinear analysis
}

\begin{abstract}
We used a two-dimensional finite element method to analyze the load-slip characteristics of nailed wooden joints sheathed with a panel. We used tests of nail bending, nail shank embedment in a wood or a panel, nailhead embedment in a face of a panel, nail withdrawing from a wood, friction between a wood and a panel, and initial axial forces of the nails. The values of the material properties for the analytical models were determined with the above tests. With a conventional one-dimensional analysis it is impossible to evaluate the shearing performance accurately because the axial forces of the nail are not calculated. Therefore, we used two-dimensional geometric nonlinear analysis. The computed load-slip curves closely matched the original experimental results; and when the friction and initial axial forces were considered, the computed curves were more likely to match the original experimental results. Our results suggested that it is better to use geometric nonlinear analysis to analyze the shearing characteristics of nailed joints, and that friction and axial forces are important factors for accurate analysis.
\end{abstract}

Key words Finite element method • Geometric nonlinearity $\cdot$ Friction $\cdot$ Single shear $\cdot$ Nail

N. Nishiyama $(\bowtie)^{1} \cdot$ N. Ando

Laboratory of Wood Based Material and Timber Engineering,

Department of Biomaterial Science, University of Tokyo, Tokyo

113-8657, Japan

\section{Present address:}

${ }^{1}$ Disaster Prevention Research Division, National Research Institute for Earth Science and Disaster Prevention, 3-1 Tennodai, Tsukuba 305-0006, Japan

Tel. +81-29-851-1611 (ext. 4109); Fax +81-29-851-1674

e-mail: tanjo@bosai.go.jp

Parts of this report were presented at the 7th World Conference on Timber Engineering, Malaysia, August 2002

\section{Introduction}

Analytical methods to evaluate load-slip characteristics of mechanical wood-joints have been established in various studies. $^{1-9}$ Generally, the yield load is estimated by a method based on the European yield theory, the stiffness is estimated by a method based on the theory of beams on elastic foundations, and the load-slip curve is calculated by methods based on the theory.

We believe there are two problems with these methods. One is that the calculated load is smaller than the actual experimental load owing to not considering the lack of effect of the fastener's axial forces, which are the forces that restrain axial displacement of the fasteners by a nut or a nail-head. It is impossible to calculate the fasteners' axial forces by conventional one-dimensional methods. The other problem is that the calculated stiffness is also quite different from the actual experimental one. ${ }^{10}$

The purpose of this study was to find a better way to calculate the load-slip curve of the nailed wood joints sheathed with a panel. We tried various methods, including one based on the small deformation theory and geometric nonlinear analysis in models of the nailed wood joints, taking into consideration the friction force between the wood and the panel and the initial axial forces of the nail.

An analytical method that considers the axial and friction forces was presented by Hirai and Wakashima. ${ }^{6-8}$ We think that with the geometric nonlinear analysis we used the axial forces can be estimated more accurately and directly by calculation, and the fastener's large deformation can be predicted more exactly by the convergence calculation than when using Hirai's method.

\section{Materials and methods}

Materials

We used medium-density fiberboard (MDF) (thickness average $8.95 \mathrm{~mm}$, density average $0.73 \mathrm{~g} / \mathrm{cm}^{3}$ ) and conifer lum- 
Fig. 1. Single shearing tests of nailed wood joints. Nail heads of type 1 touched the face of the medium-density fiberboard; (MDF). Type 2 nails were pounded more deeply than type 1 nails based on the thickness of the nail head
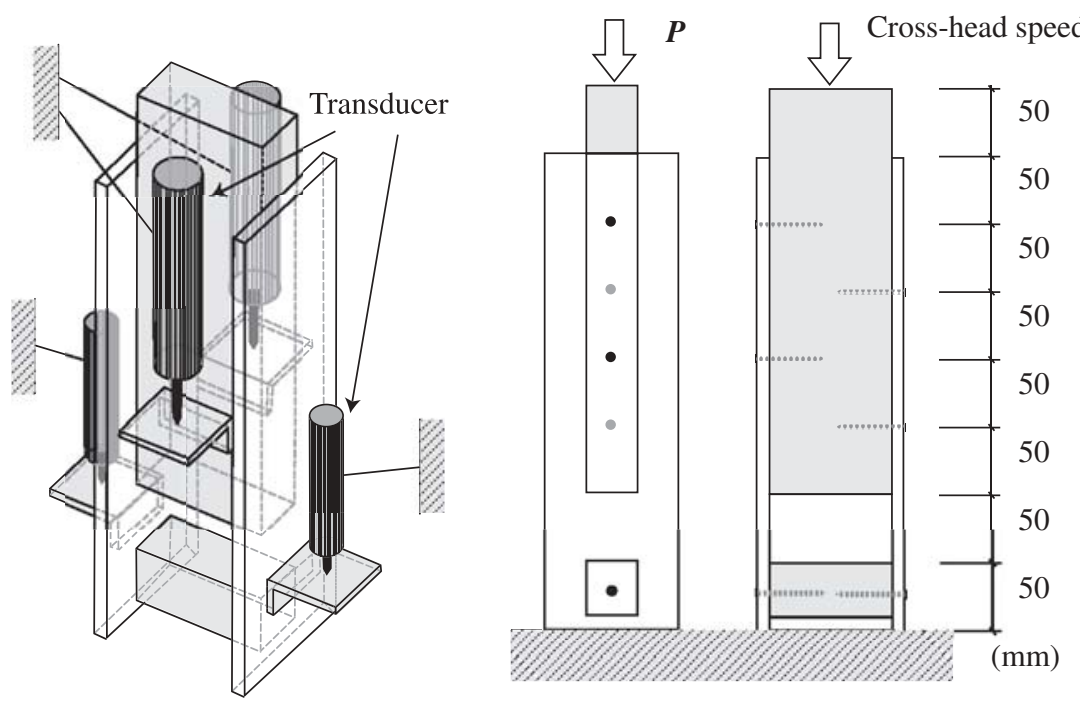

$: 2 \mathrm{~mm} / \mathrm{min}$

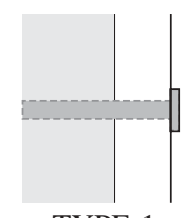

TYPE-1

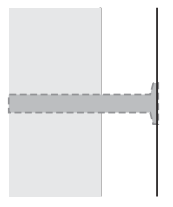

TYPE-2

$n=6$

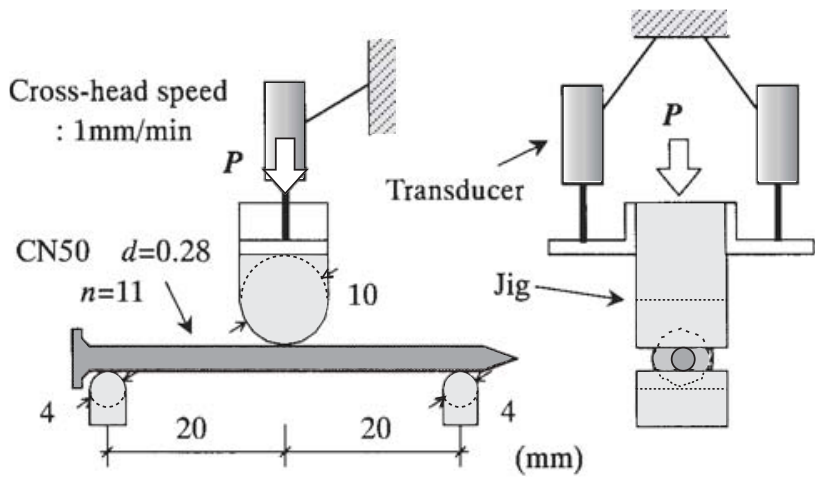

Fig. 2. Nail-bending tests. $P$, applied load

ber for wood frame construction (S-P-F 204) (density average $\left.0.54 \mathrm{~g} / \mathrm{cm}^{3}\right)$. The nails were CN50.

\section{Methods}

We constructed the test specimens for single shearing tests of nailed wood joints, among which there were two types (for type 1 the nail head was not pounded into the panel, and for type 2 the nail head was pounded into the panel) (Fig. 1): test specimens for nail-bending tests (Fig. 2), test specimens for nail pull-out tests (Fig. 3); test specimens for lateral nail resistance tests (Fig. 4); and test specimens for nail head pull-through tests (Fig. 5). For the lateral nail resistance tests, the gaps between the specimen and the jig were within $0.02 \mathrm{~cm}$, and the length/diameter ratio was 3.21 . These tests, except for the nail head pull-through tests were done under monotonic loading.

Figure 6 shows a typical nail head pull-through test. First, the nail is not fully pounded into the MDF, and the nail head does not touch the face of the MDF. The nail is then pulled at a steady speed of $2 \mathrm{~mm} / \mathrm{min}$. As soon as the nail head touches the face of the MDF, the pulling is stopped and the force is fully released. Pulling begins again at the

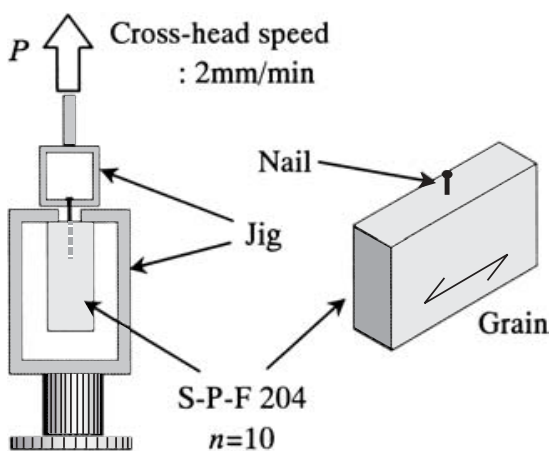

Fig. 3. Nail pull-out tests. Displacement of the crosshead was measured. $S-P-F$, conifer lumber for wood frame construction
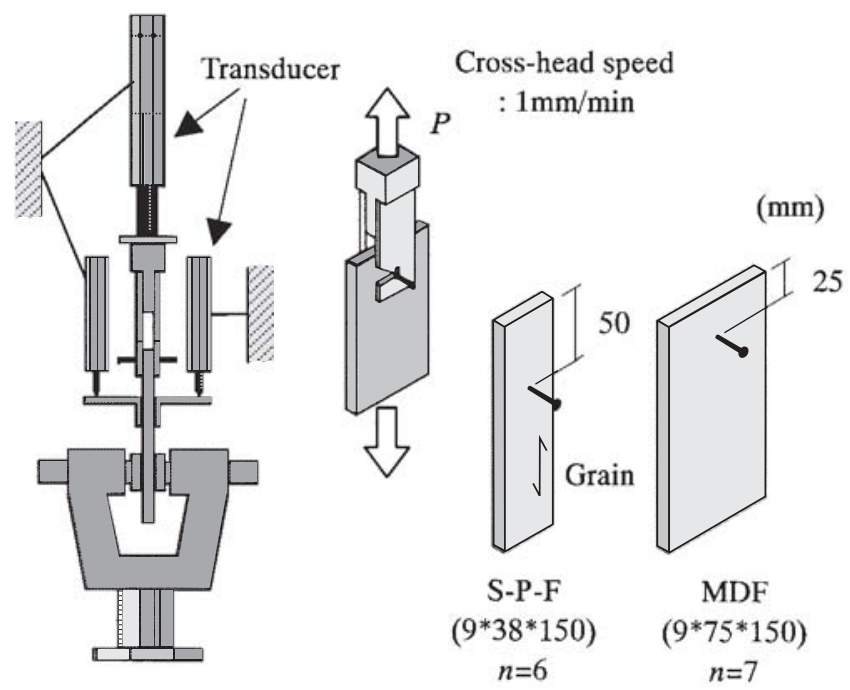

Fig. 4. Lateral nail resistance tests 


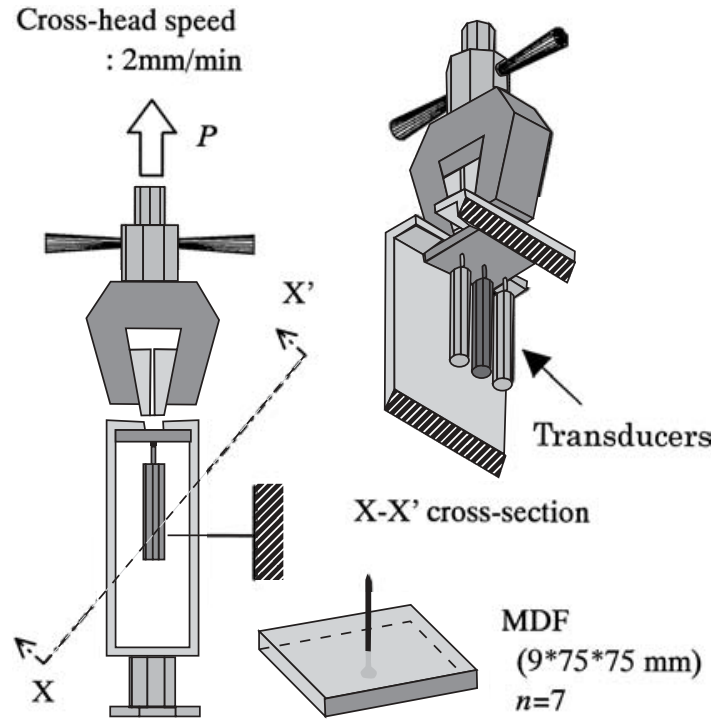

Fig. 5. Nail head pull-through tests

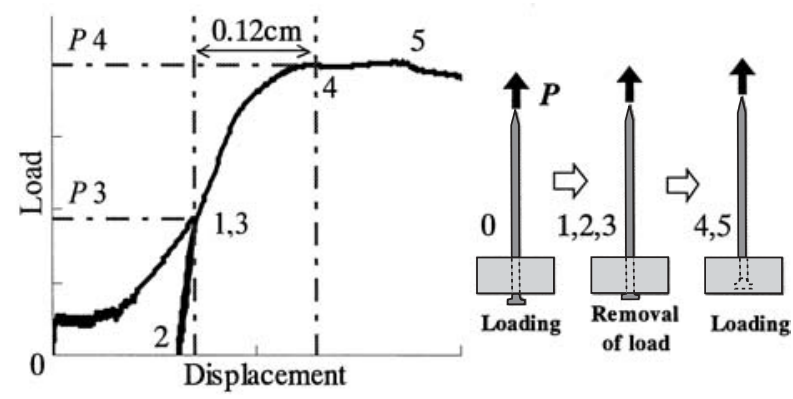

Fig. 6. Loading during the nail head pull-through test

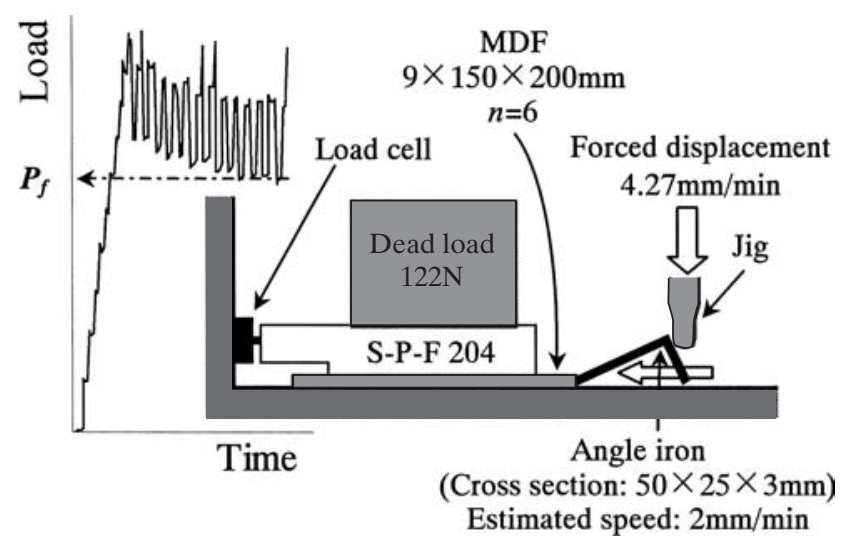

Fig. 7. Rubbing test and valuation method for coefficient of dynamic friction. $P_{\mathrm{f}}$, dynamic friction force

same speed until the force decreases to $80 \%$ of the maximum load.

Figure 7 shows the schema for the rubbing test and for evaluating the dynamic friction coefficient. The MDF was moved in a horizontal direction, and the friction forces between the MDF and the S-P-F were measured with the load

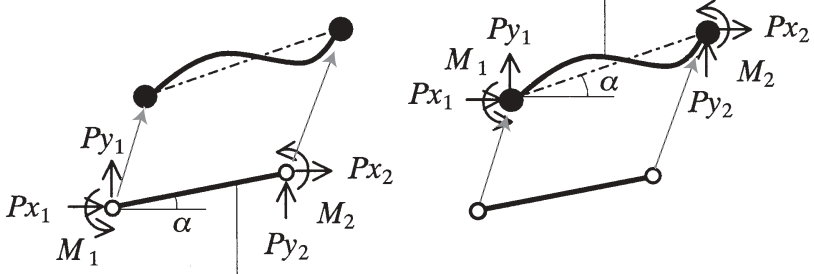

An element before load application

Fig. 8. Difference between the small deformation theory and geometric nonlinear analysis. Left Small displacement theory. Right Geometric nonlinear analysis. $P_{x 1}, P_{y 1}, M_{1}$, forces at the first node; $P_{x 2}, P_{y 2}, M_{2}$, forces at the second node; $\alpha$, slope of the element

cell touching the S-P-F. The coefficient was calculated by the formula

$$
C_{\mathrm{df}}=P_{\mathrm{f}} /\left(W_{\mathrm{dl}}+W_{\mathrm{spf}}\right)
$$

where $C_{\mathrm{df}}$ is the coefficient of dynamic friction; $P_{\mathrm{f}}$ is the friction force as indicated in Fig. 7; $W_{\mathrm{dl}}$ is the weight of the dead load (N); and $W_{\text {spf }}$ is the weight of the S-P-F $(\mathrm{N})$.

\section{Numerical solution}

We simulated the load-slip characteristics of the single shear nailed wood joints sheathed with MDF. The models were computed by the load-incremental method of the finite element method (FEM). In addition, the stiffness and strength were calculated by conventional analytical methods based on the theory of beams on elastic foundations and the European yield theory.

Finite element method

\section{Techniques}

The FEM is classified into two categories. One is a method based on the small deformation theory, and the other is geometric nonlinear analysis for large deformation. With the small deformation theory, the equilibrium equations are based on the undeformed geometry before load application. For the geometric nonlinear analysis, equilibrium is based on the real deformed configurations, as shown in Fig. 8. The details are described elsewhere. ${ }^{11,12}$

When the load on a geometrically nonlinear structure is applied in small increments, the force and displacement may be related by

$$
\left[S_{\mathrm{t}}\right]_{m}\{\Delta D\}_{m}=\{\Delta F\}_{m}
$$

where $\{\Delta F\}_{m}$ and $\{\Delta D\}_{m}$ are increments of forces and displacements. The tangent stiffness matrix $\left[S_{t}\right]_{m}$ changes with the change in geometry, and $\left[S_{\mathrm{t}}\right]_{m}$ depends on the internal forces. $\left[S_{t}\right]_{m}$ is expressed as the sum of two matrices

$\left[S_{\mathrm{t}}\right]_{m}=\left[S_{\mathrm{e}}\right]_{m}+\left[S_{\mathrm{g}}\right]_{m}$ 
where $\left[S_{\mathrm{e}}\right]_{m}$ is the elastic stiffness matrix, and $\left[S_{\mathrm{g}}\right]_{m}$ is the geometric stiffness matrix. The two matrices vary during the analysis. If the change in geometry and internal forces are neglected, $\left[S_{\mathrm{t}}\right]_{m}$ is the tangent matrix based on the small deformation theory.

In our geometric nonlinear analysis, we considered only the geometric nonlinearity of the beam elements and intentionally did not consider that of the axial springs. The material nonlinearity was considered in both the small deformation theory and the geometric nonlinear analyses. As for the beam elements in the geometric nonlinear analysis, $\left[S_{\mathrm{e}}\right]_{m}$ was expressed as a function of length and slope $\alpha$ of the beam element internal forces $P_{x 1}^{*}$ in Fig. 9, and Young's modulus of the fastener. $\left[S_{\mathrm{g}}\right]_{m}$ was expressed as a function of length and slope $\alpha$ of the beam element and internal forces $P_{x 1}^{*}$ and $P_{y 1}^{*}$ in Fig. 9. As for the beam elements in the small deformation theory, the length and slope of the beam element were assumed to be constant in the initial position, and the internal forces were neglected. Then $\left[S_{\mathrm{g}}\right]_{m}$ was zero

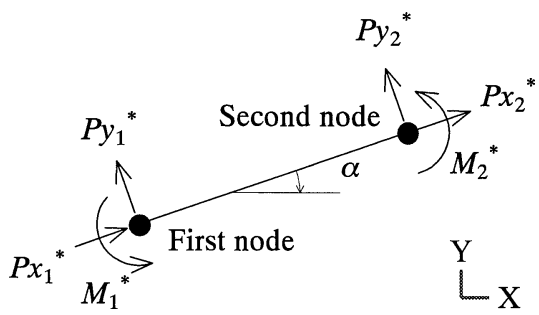

Fig. 9. Coordinate system for a beam element. $P x_{1}^{*}, P y_{1}^{*}, M_{1}^{*}$, internal forces at the first node in local directions; $P x_{2}^{*}, P y_{2}^{*}, M_{2}^{*}$, internal forces at the second node in local directions; $\alpha$, slope of the beam element matrix, and $\left[S_{\mathrm{e}}\right]_{m}$ was expressed as a function of Young's modulus of the fastener. As for the spring elements in both analytical methods: $\left[S_{\mathrm{t}}\right]_{m}$ was based on the small deformation theory, $\left[S_{\mathrm{g}}\right]_{m}$ was zero matrix, and $\left[S_{\mathrm{e}}\right]_{m}$ was expressed as a function of the spring constant. The stiffness matrices were described previously. ${ }^{13}$

Analysis involving iteration is necessary if both material and geometric nonlinearities are considered. The analysis was done using Newton-Raphson's technique.

The iteration cycles were terminated when the following criterion was satisfied

$$
\left(\{g\}^{T}\{g\}\right)^{1 / 2}=\beta\left(\{F\}^{T}\{F\}\right)^{1 / 2}
$$

where $\beta$ was the tolerance value, which we made 0.005 for the small deformation theory or 0.01 for the geometric nonlinear analysis because the process of convergence in the geometric nonlinear analysis was more complicated than that in the small deformation theory. This criterion ensured that the out-of-balance forces $\{g\}$ were small compared with the incremental forces $\{F\}$.

The matrix was calculated by the Gauss-Jordan elimination, which included complete pivoting.

\section{Analytical models}

Table 1 shows scheme of the computation models. We made two beam-spring models for single shearing analysis of the nailed wood joints sheathed with MDF: model 1 and model 2 (Fig. 10). The springs used are indicated in Table 2.

In both models 1 and 2 the nail shank is modeled using 50 beam elements with rotation spring elements at both ends of each beam element (Fig. 11), among which 20 on the side

Table 1. Scheme of the computation models

\begin{tabular}{lllll}
\hline $\begin{array}{l}\text { Model } \\
\text { name }\end{array}$ & $\begin{array}{l}\text { Model } \\
\text { no. }\end{array}$ & $\begin{array}{l}\text { Geometric nonlinearity } \\
\text { (only the beam elements) }\end{array}$ & $\begin{array}{l}\text { Friction and } \\
\text { initial axial force }\end{array}$ & Object (type) \\
\hline H1-sma & 1 & Neglected & Neglected & 1,2 \\
H1-geo & 1 & Considered & Neglected & 1,2 \\
S1-sma & 2 & Neglected & Neglected & 1,2 \\
S1-geo & 2 & Considered & Neglected & 1,2 \\
F1-geo & 2 & Considered & Considered & 1 \\
F2-geo & 2 & Considered & Considered & 2 \\
\hline
\end{tabular}

Table 2. Springs in the computation models

\begin{tabular}{|c|c|c|c|}
\hline Spring no. ${ }^{a}$ & Type & Direction & Experiment and object \\
\hline $\mathrm{X} 1$ & Axial & $\mathrm{X}$ & $\begin{array}{l}\text { Pull-out tests of nails } \\
\text { Withdrawing of nail from the S-P-F }\end{array}$ \\
\hline $\mathrm{X} 2-\mathrm{X} 42$ & Axial & $\mathrm{X}$ & $\begin{array}{l}\text { Nail-head pull-through tests } \\
\text { Embedment of nail-head in the MDF }\end{array}$ \\
\hline Y1-Y31 & Axial & $\mathrm{Y}$ & $\begin{array}{l}\text { Lateral nail resistance tests of the S-P-F } \\
\text { Embedment of nail shank in the S-P-F }\end{array}$ \\
\hline Y32-Y52 & Axial & $\mathrm{Y}$ & $\begin{array}{l}\text { Lateral nail resistance tests of the MDF } \\
\text { Embedment of nail shank in the MDF }\end{array}$ \\
\hline R1-R100 & Rotation & $\theta$ & $\begin{array}{l}\text { Bending tests of nail shank } \\
\text { Nonlinearity of nail bending }\end{array}$ \\
\hline
\end{tabular}

S-P-F, conifer lumber for wood frame construction; MDF, medium-density fiberboard

${ }^{a}$ Spring numbers are indicated in Fig. 9 

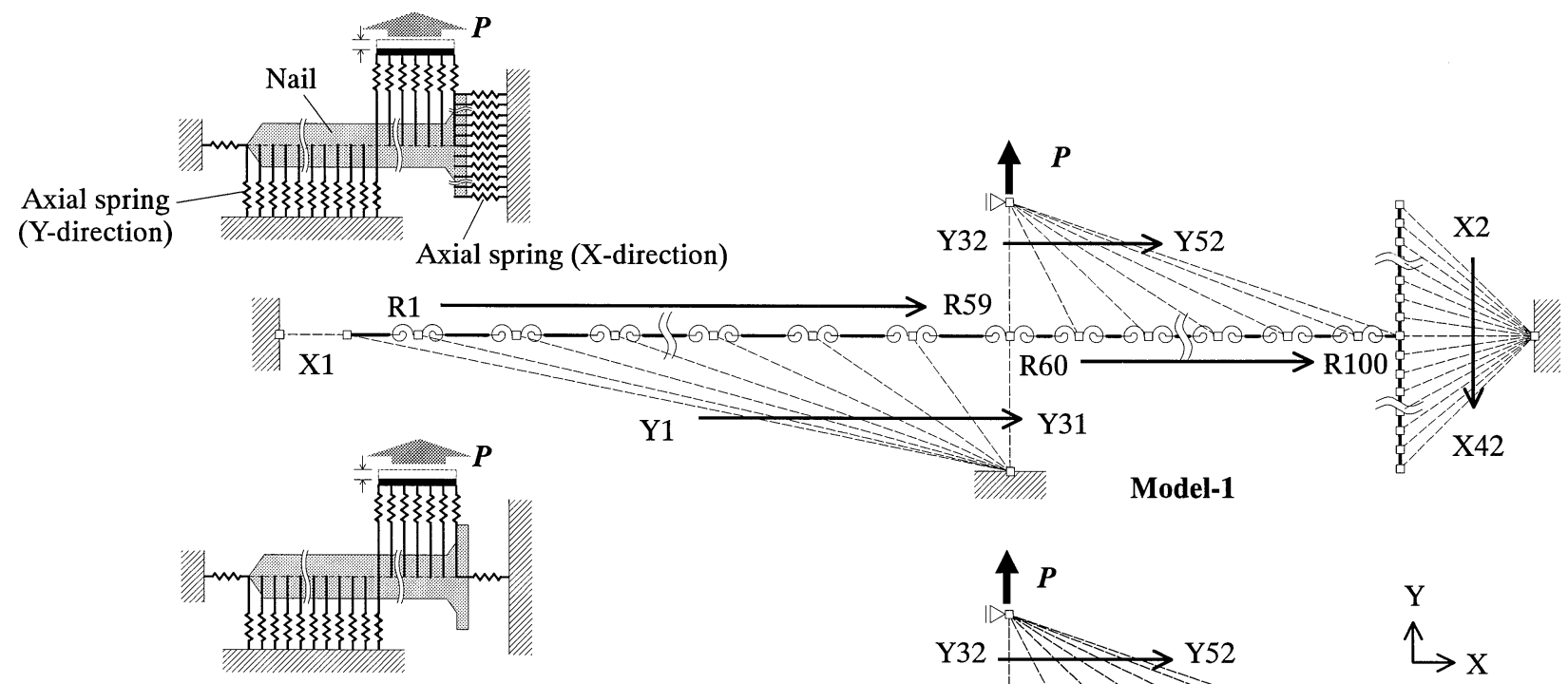

Model-1

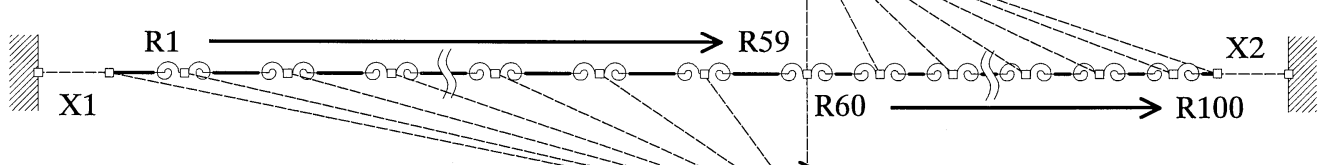

Y1

Fig. 10. Model of the nailed joint sheathed with MDF. Squares, nodes; broken lines, axial spring elements; heavy solid lines, beam elements. $X 1$ to $X 42, Y 1$ to $Y 52$, and $R 1$ to $R 100$ are the spring numbers listed in

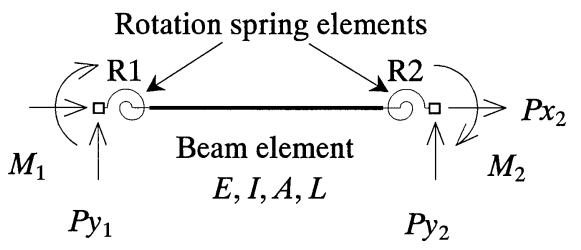

Fig. 11. Elements of the nail shank. $E$, Young's modulus; $I$, geometrical moment of inertia; $A$, Cross-sectional area; $L$, length of the beam element; $R 1$ and $R 2$, nonlinear rotation springs (moment-rotation angle curves of R1 and R2 were assumed to be the same)

of the nail head are in the MDF and the other 30 are in the S-P-F. The length of the beam elements of the models for type 1 is different from that for type 2 . In the analysis F2geo of type 2 (Table 1 ), the length of the part of the nail shank touching the MDF is $7.75 \mathrm{~mm}(8.95-1.20 \mathrm{~mm})$ and that touching the S-P-F is $42.25 \mathrm{~mm}(50.00-7.75 \mathrm{~mm})$, where $8.95 \mathrm{~mm}$ is the thickness of the MDF and $1.20 \mathrm{~mm}$ is the thickness of the nail head. The other analysis, the length of the part of the nail shank touching the MDF, is $8.95 \mathrm{~mm}$ and that touching the S-P-F is $41.05 \mathrm{~mm}$. Nonlinearity associated with the axial forces of the nail is intentionally neglected, so each beam element can be assumed to be an elastic body. Nonlinearity associated with bending of the nail is simulated by the rotation springs (Fig. 12). The embedment is expressed by axial springs (Fig. 10). The forces of the axial springs were assumed to depend on the relative displacement in the $x$-direction or $y$-direction between the first and second nodes as described in Table 2. The broken
Table 2. We considered only the geometric nonlinearity of the beam elements in the geometric nonlinear analysis
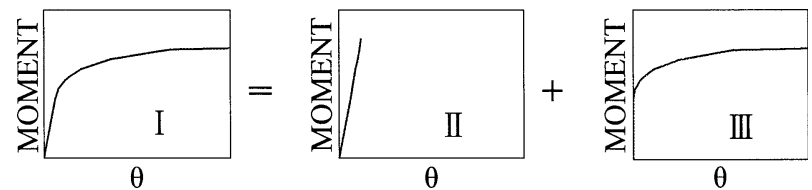

Fig. 12. Modeling method of nonlinearity of the nail shank. I, bending of the nail; $I I$, beam element; $I I I$, rotation springs

lines representing axial springs in Fig. 10 indicate the location of the first and second nodes of the spring elements; they do not express vectors of the springs.

With conventional methods, the nail shank embedment is modeled by elements based on the theory of beams on elastic foundations. Theoretically, the calculated load-slip relation of the models using fewer axial springs is different from that of models using elastic foundations, but the difference can be reduced to a negligible level by increasing the number of axial springs.

In model 1 the nail head is modeled using 40 beam elements, each of which is assumed to be an elastic body. In model 2 the nail head is not modeled and is assumed to have free rotation.

\section{Input data processing}

The original experimental data were processed and manifested by polygonal lines before the FEM analysis (Fig. 13). The load-displacement relation of the axial springs and Young's modulus of the beam elements were determined 


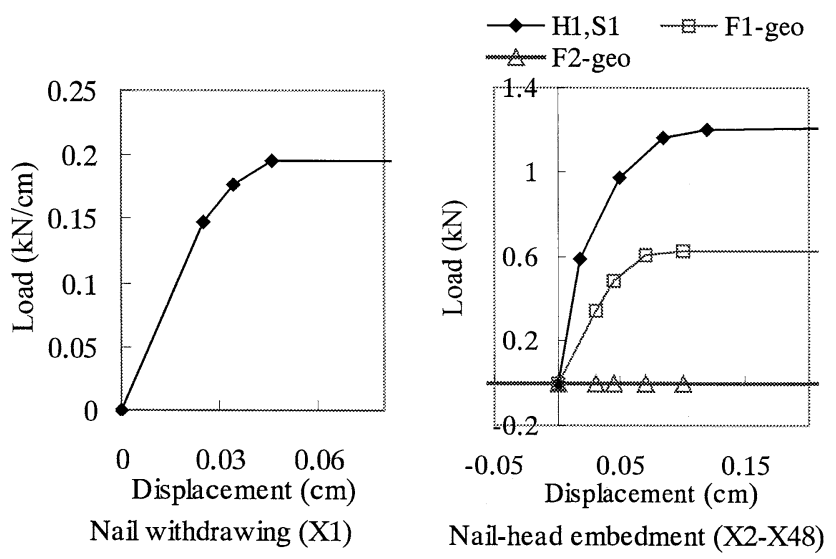

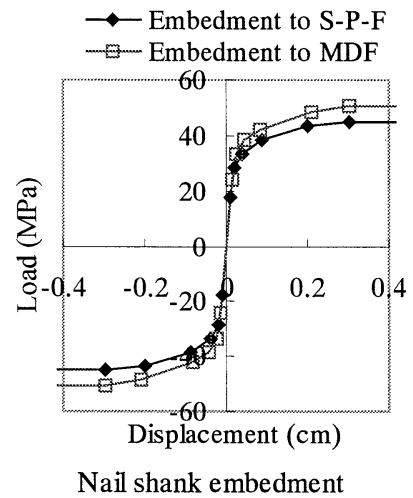

(Y1-Y51)

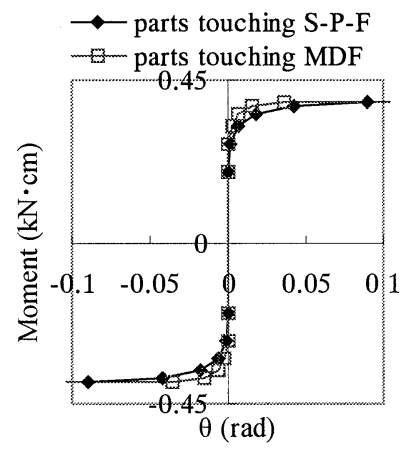

Nonlinearity of the nail shank

(R1-R51)

Fig. 13. Input data of the springs for the computation models

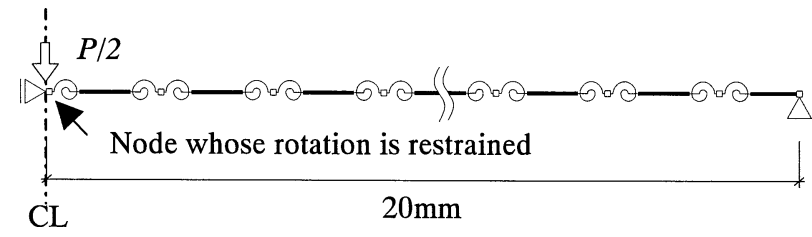

Fig. 14. Beam-spring model for nail-bending tests. $P / 2$, half of the applied load in the nail bending test; $C L$, center line

from the average of the experimental values. Young's modulus for the beam elements is $185.5 \mathrm{GPa}$.

The moment-rotation relation of the rotation springs is determined by trial and error so that the calculated result of the beam-spring model (Fig. 14) fits the load-displacement curve of the nail-bending tests (Fig. 2). Only the right half of a nail-bending test is simulated in the model shown in Fig. 14 because the whole test body is symmetrical.

It is assumed that the axial springs from X2 to X48 in Fig. 10 show resistance against the deformation only in the area where the nail head is embedded in the MDF. For the computation models $\mathrm{H} 1$ and $\mathrm{S} 1$ in which the friction between MDF and S-P-F is not considered, the curve segment from 2 to 5 in Fig. 6 was used as the input data. For F1-geo and F2-geo, we considered not only the friction but also the initial forces. For F1-geo, the curve segment from 3 to 5 was used as the input data; and the tensile force, which was equal to $P 3$ was applied to the nail head and the nail tip because an initial force $P 3$ was generated when the nail head touched the MDF.

For F2-geo, the curve segment from 4 to 5 was used as the input data; and a tensile force, which is equal to the initial force $P 4$, was applied to the nail because the nail heads of type 2 were pounded into the MDF (the nail head thickness was $0.12 \mathrm{~cm}$, and the nail head surface was at the same level as the MDF surface).

The dynamic friction coefficient between the MDF and the S-P-F was 0.166 , which was a calculated average value from the rubbing tests shown in Fig. 7. The friction force was calculated from the axial force of the spring X2 in Fig. 10.
Conventional analytical methods

The initial stiffness was calculated based on the theory of beams on elastic foundations. The yield load and the maximum load were calculated by the European yield theory. The calculation was conducted referring to other people's methods, and the parameters were similarly determined by lateral nail resistance tests and nail bending tests. ${ }^{9}$ The maximum load was calculated from the maximum stress in the lateral nail resistance tests and the maximum moment in the nail-bending tests. The slope between $10 \%$ and $40 \%$ of the maximum load in the lateral nail resistance tests was used to calculate the initial stiffness.

\section{Results and discussion}

Figure 15 shows the results of the nail deflection calculated by S1-sma and F1-geo computational models. The righthand side shows the results of the F1-geo geometric nonlinear analysis. The figure shows that there were nail head embedment on the upper right side and nail withdrawal on the lower left side. In this case, the calculated nail length was near its actual length. The left-hand side shows the calculated results by the small deformation theory, in which the nail nodes did not move in the direction perpendicular to that of loading, there was no nail-head embedment or nail withdrawal, and the calculated nail length was longer than its actual length. This is because the axial forces were not counted using the small deformation theory in which the equilibrium is based on the node position before load application.

Figure 16 compares the original experimental results and the calculated results, neglecting the friction force in the single shearing tests. Although the maximum loads of types 1 and 2 were almost the same, their load-slip curves were different until the maximum load. The stiffness of type 1 was less than that of type 2 .

The calculated curves by geometric nonlinear analysis were more consistent with the experimental curves than 


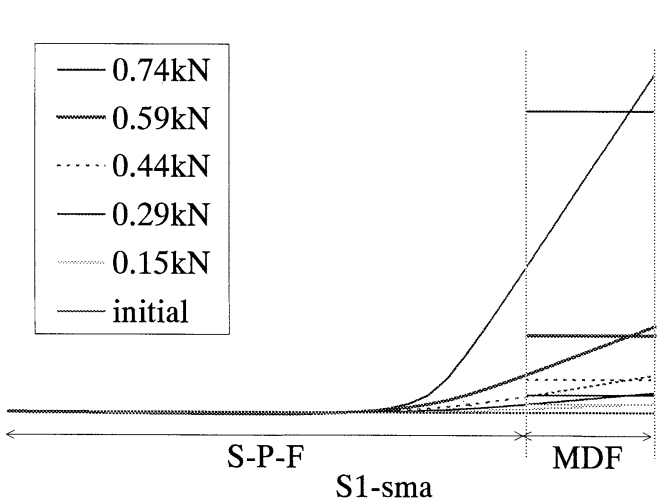

The small deformation theory

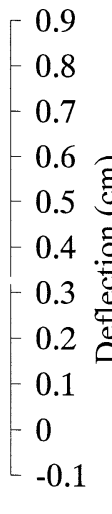

0.8

0.7

0.5

0.4

3

$.2 \stackrel{\square}{\triangle}$

0.1

$-0.1$
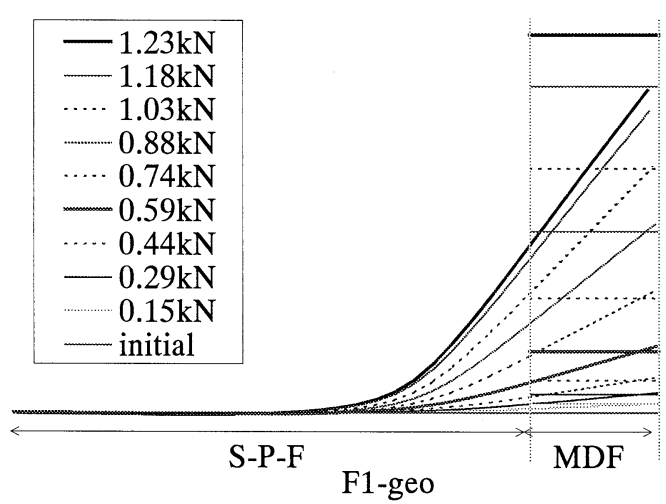

geometric nonlinear analysis

Fig. 15. Nail deflected shape (theoretical)
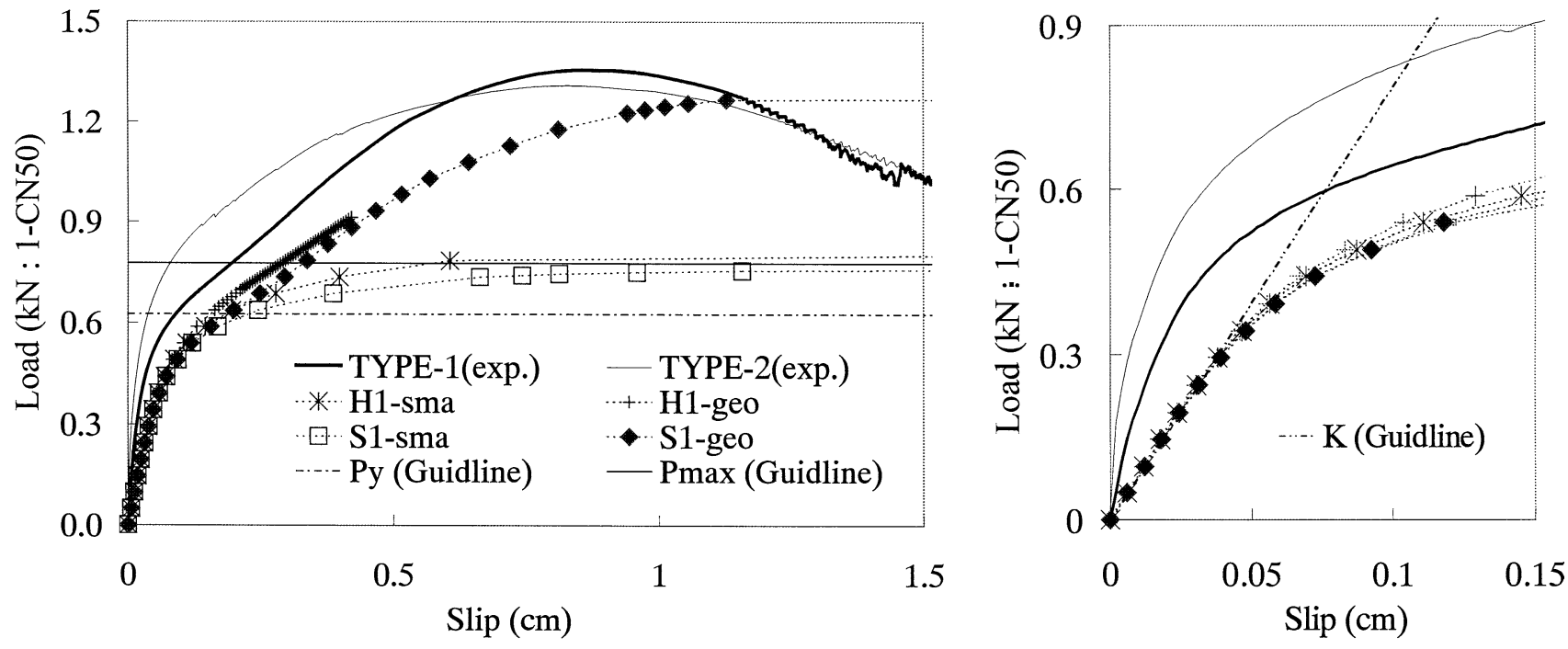

Fig. 16. Comparison of the original experimental results of the single shearing tests and the calculated results, with the friction and initial force neglected

those calculated according to the small deformation theory. The determining factors of the calculated ultimate shearing strength by each analytical method were different. The determining factors in the small deformation theory were based on nail bending, and those in the geometric nonlinear analysis were based on nail shank embedment in the MDF, as shown in Fig. 15. Therefore, the calculated curves by each method were different.

With the small deformation theory the nail started to yield at loads below $0.8 \mathrm{kN}$, but with the geometric nonlinear analysis the yielding load exceeded $0.8 \mathrm{kN}$ because of the effect of the axial force of the nail shank. The mechanism of this phenomenon is that the nail head resists embedment into the face of the MDF. Moreover, tensile stress is generated in the nail shank, which makes the nail shank difficult to bend and accounts for the load increase in the single shearing tests of the nailed joints.

The results calculated by both the European yield theory and the theory of beams on elastic foundations are also shown in Fig. 16, in which $K$ is the initial stiffness, $P_{\mathrm{y}}$ is the yield load, and $P_{\max }$ is the maximum load. The results calculated according to the European yield theory were similar to those found by the small deformation theory but were different from the original experimental values.

As for the initial stiffness, all the calculated values were almost the same but were different from the original experimental values. Moreover, the calculated stiffness by the model H1-geo in which the nail head was modeled was almost the same as that found by the model S1-geo in which the nail head was not modeled. This indicates that the rotation of the nail head was hardly restrained.

Figure 17 compares the experimental and calculated results of type 1 with the friction and the initial axial forces considered. Figure 18 compares the experimental and calculated results for type 2, with the friction and initial axial forces considered.

For both types 1 and 2, the calculated load-slip curves, taking into consideration the friction and the axial force, 


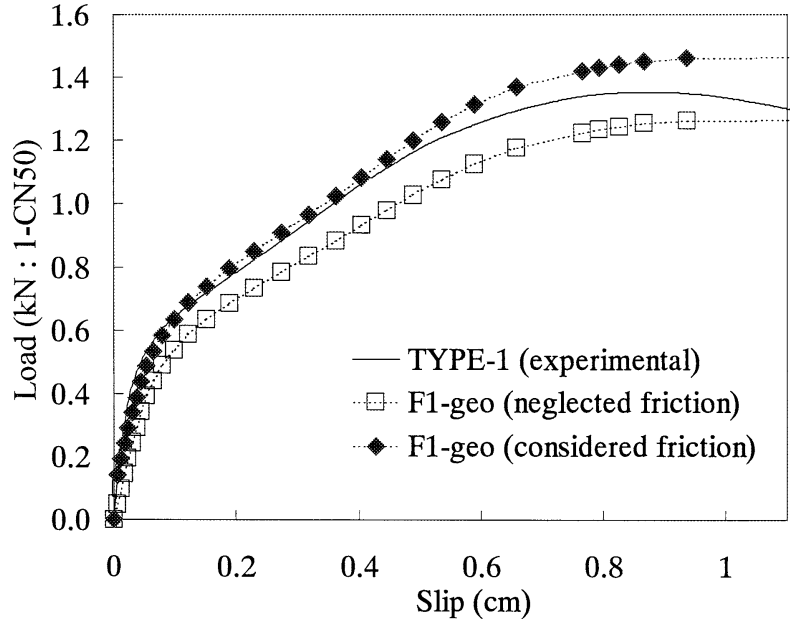

Fig. 17. Comparison of experimental and calculated results, with the friction and the initial force considered: TYPE-1

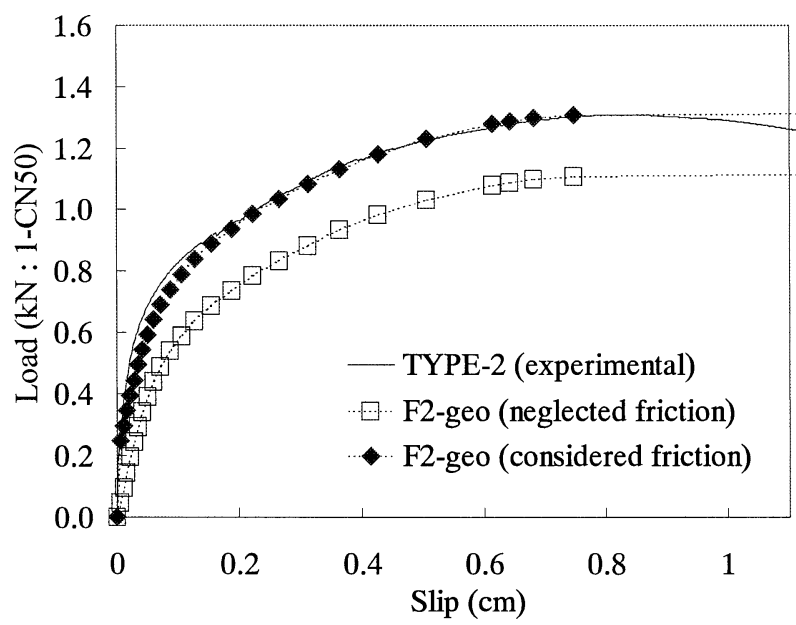

Fig. 18. Comparison between experimental and calculated results, with the friction and the initial force considered: TYPE-2

were overall similar to the original experimental ones. The friction and the axial force may reflect a difference of the nail head position or embedment depth between types 1 and 2.

As for the initial stiffness when considering friction, the calculated value closely matched the original experimental value, though not exactly. The difference between the calculated value and the original experimental value is due to the fact that in both of these analytical models the effect of nail bending in the lateral nail resistance tests was not excluded and the friction coefficient was set up as a constant. We think that the difference will diminish if we get rid of the effect of the nail bending and adjust the friction coefficient depending on the displacement.

\section{Conclusions}

The results of our study suggest that geometric nonlinear analysis is a relatively better method for evaluating load-slip curves of nailed wood joints. The calculated results closely matched the original experimental ones when the friction between the S-P-F and the MDF as well as the initial axial forces of the nail are considered in the calculation.

Furthermore, this analytical method may make it possible to evaluate precisely the load-slip characteristics of various nailed wood joints by simple tests such as those we used in our study. They can be applied not only to the evaluation of structural designs but to new material development, such as with materials for structural panels.

Acknowledgment The authors thank Noda Corp. for kindly offering us the MDF.

\section{References}

1. Foschi RO (1974) Load-slip characteristics of nails. Wood Science 7:69-76

2. Foschi RO (1977) Load-slip characteristics for connections with common nails. Wood Science 9:118-123

3. Tsujino T, Hirai T (1983) Nonlinear load-slip relationship of bolted wood-joints with steel side-members. I. Numerical analysis based upon a finite element method (in Japanese). Mokuzai Gakkaishi 29:833-838

4. Hirai T (1983) Nonlinear load-slip relationship of bolted woodjoints with steel side-members. II. Application of the generalized theory of a beam on an elastic foundation. Mokuzai Gakkaishi 29:839-844

5. Komatsu K (1988) Analysis of glulam frame structures considering nonlinear characteristics of fasteners. 1. Derivation of analytical method (in Japanese). Mokuzai Gakkaishi 34:581-589

6. Hirai T (1990) Load-slip relationship of mechanical wood-joints with steel webs (in Japanese). Res Bull Hokkaido Univ For 47:215-248

7. Hirai T (1991) Analyses of the lateral resistance of bolt joints and drift-pin joints in timber. II. Numerical analyses applying the theory of a beam on an elastic foundation (in Japanese). Mokuzai Gakkaishi 37:1017-1025

8. Hirai T, Wakashima Y (1996) Lateral resistance and fracture modes of nailed timber joints. III. Numerical analyses of maximum lateral resistance of nailed timber-plywood joints (in Japanese). Mokuzai Gakkaishi 42:1195-1201

9. Japan $2 \times 4$ Builders Association (1998) Structural design guidelines for wood frame construction (in Japanese). Japan $2 \times 4$ Builders Association, Tokyo, pp 56-63, 186-192, 219-220

10. Ohno T, Okabe M, Kawai N, Takada S (1999) Shear strength properties of shear walls in wood-frame construction. Part 2. Single shear tests on nailed joints and adaptability of yield theory (in Japanese). In: Summaries of technical papers of annual meeting. Architectural Institute of Japan, Tokyo, C-1, pp 97-98

11. Ghali A, Neville AM (1997) Structural analysis: A unified classical and matrix approach, 4th edn. Spon, London, pp 361-370, 698-728

12. Ghali A, Neville AM, Kawakami M (2001) Structural analysis: a unified classical and matrix approach (in Japanese). Gihodo Shuppan, Japan, pp 161-170, 371-402

13. Nishiyama N, Ando N. Analysis of double shearing characteristics of bolted timber joints with rope effect: application of geometric nonlinear analysis (in Japanese). Mokuzai Gakkaishi (in press) 